\title{
A MEDIAÇÃO NO DIREITO BRASILEIRO E SUA EFETIVIDADE NO ÂMBITO DAS SERVENTIAS EXTRAJUDICIAIS
}

\section{MEDIATION IN BRAZILIAN LAW AND THEIR EFFECTIVENESS WITHIN THE GROUND OF EXTRAJUDICIAL SERVICES}

\author{
${ }^{1}$ Marcelo Lessa da Silva
}

\section{RESUMO}

O presente trabalho objetivou analisar a evolução da política nacional de pacificação social e de resolução de conflitos por meio da mediação. Como foco principal, analisou-se a efetividade da mediação nas serventias extrajudiciais e a interpretação aplicada ao artigo 42 da lei de mediação brasileira. Utilizou-se o método de pesquisa teórico-dogmática, exploratório e explicativo, com técnica de coleta e análise, documental e bibliográfica. Evidenciou-se que o legislador reconheceu a necessidade de utilização das serventias extrajudiciais na implementação da cultura de paz e da autocomposição na resolução dos conflitos.

Palavras-chave: Mediação extrajudicial. Mediação nos Cartórios. Lei n ${ }^{\circ}$ 13.140/2015. Mediação. Novo CPCB

\begin{abstract}
The present paper aimed to analyze the evolution of the national policy of social pacification and conflict resolution through mediation. The main focus was to analyze the effectiveness of mediation in extrajudicial services and the interpretation applied to article 42 of the Brazilian mediation law. The method of theoretical-dogmatic research, exploratory and explanatory was used, with collection and analysis technique, documentary and bibliographical. It was pointed out that the legislator recognized the need to use extrajudicial services in the implementation of a culture of peace and self-determination in resolving conflicts.
\end{abstract}

Keywords: Extrajudicial mediation. Notary's office mediation. Law 13.140/2015. Mediation. New CPCB

1 Doutorando em Direito Civil pela Universidad de Buenos Aires - UBA, (Argentina). Professor de Direito da Universidade Federal do Rio de Janeiro - UFRJ, Rio de Janeiro. E-mail: marcelolessa.federal@ yahoo.com.br 


\section{INTRODUÇÃO}

O direito brasileiro vive um momento de muitas transformações. Com o intuito de caminhar paralelamente e na mesma intensidade dos movimentos sociais, algumas mudanças estão sendo realizadas para que haja a eficiência esperada da justiça frente a um sistema jurídico moroso e sobrecarregado de demandas.

A mediação é uma dessas importantes transformações e atua como base para o surgimento de uma política jurídica de autocomposição dos conflitos, de forma a prevenir ou pôr fim aos litígios, sendo utilizada como meio efetivo de pacificação social.

Neste cenário, a Resolução nº 125/2010 do Conselho Nacional de Justiça foi um marco na implementação de uma política judiciária de estímulo, apoio e difusão permanente de mecanismos consensuais e de sistematização e aprimoramento das práticas já adotadas pelo judiciário na solução dos litígios. A resolução incorporou a mediação nos processos já em tramitação e ainda nos que não se iniciaram, como forma pré-processual.

No mesmo caminho, o novo Código de Processo Civil (Lei nº 13.105/2015) instituiu o dever do Estado de promover o incentivo a uma solução consensual dos conflitos, com a criação de centros judiciários nos tribunais para realização de audiências e sessões de conciliação e mediação, sem exclusão de outras formas de conciliação e mediação extrajudiciais, realizadas por meio de profissionais independentes e de órgãos institucionais.

De maneira mais focada, a Lei de Mediação $n^{\circ} 13.140 / 2015$, traz os procedimentos e conceitos que serão adotados na mediação judicial e na extrajudicial, bem como a sua aplicação. Em conjunto com o novo CPC, atua na consolidação da política judiciária de desjudicialização e de consensualização contribuindo na formação de uma cultura estimuladora e difusora de autocomposição.

Deste modo o presente trabalho teve como objetivo demonstrar a evolução da política nacional de pacificação social e de resolução de conflitos por meio da mediação. Buscou-se demonstrar sua relevância como importante instrumento auxiliador na implantação desta política, bem como os instrumentos jurídicos que a regem com suas características e peculiaridades.

Como foco principal, analisou-se a medição no âmbito das serventias extrajudiciais, sendo este um importante meio de operacionalizar a realização das mediações, tendo em vista a grande acessibilidade que os cartórios possuem por estarem instalados em todas as cidades do território nacional, facilitando sobremaneira o acesso interessados. 
Para tanto, utilizou-se do método de pesquisa teórico-dogmática, exploratório e explicativo, com técnica de coleta e análise, documental e bibliográfica.

\section{A MEDIAÇÃO E SUA EVOLUÇÃO NO ORDENAMENTO JURÍDICO BRASILEIRO}

Com o movimento mundial de acesso à justiça, iniciado ainda na década de 70, devido à crise no judiciário que não possui condições de lidar com a quantidade e complexidade de todos os conflitos existentes na sociedade, acarretando morosidade, insatisfação das partes e, quiçá, descrédito na resolução dos problemas, há uma crescente onda com vistas à solução de disputas através da negociação autônoma dos cidadãos, auxiliando na melhoria das relações sociais envolvidas (Manual de Mediação Judicial CNJ, 2015. p. 26).

Desta forma, o Estado brasileiro vem, desde o início da última década, positivando a mediação como uma das soluções alternativas à litigiosidade. Nesse escopo, inserem-se as grandes mudanças ocorridas recentemente na legislação pátria, que culminou com a edição da Lei $n^{\circ} 13.140 / 2015$, que regulamenta o procedimento da mediação, tanto no âmbito judicial quanto no extrajudicial, confirmando a tendência de solução pacífica dos conflitos, tendo sido, inclusive, posta como etapa do processo judicial, chegando a ser requisito da petição inicial (art. 319, VII, NCPC).

A mediação pode ser conceituada como um método não-adversarial, baseado no restabelecimento do diálogo, na busca do olhar para o outro, na resolução integral do conflito sem restringir-se à lide em si, de modo rápido e eficaz, sendo conduzida por um mediador neutro, com habilidades de comunicação e negociação, imparcial e paciente (Manual de Mediação Judicial do CNJ, 2015, p.20).

Para Vasconcelos (2008, p. 36) a mediação é um meio de solução de disputas em que não se utiliza a hierarquia, havendo necessariamente a colaboração de um terceiro chamado mediador, sendo este apto, imparcial, independente e de livre escolha ou aceitação dos

mediados. Estes apresentarão o problema ao mediador que os escutará e os questionará, procurando criar um diálogo construtivo cujo objetivo maior será a firmação de um eventual acordo.

O parágrafo único do artigo $1^{\circ}$ (Lei 13.140/2015), conceitua o instituto como uma atividade técnica exercida por terceiro imparcial sem poder decisório, escolhido ou aceito pelas partes, que as auxilia e estimula a identificarem ou desenvolverem soluções consensuais para a controvérsia 
Ademais, referido diploma ainda traz consigo a figura do mediador, que será o responsável por conduzir o procedimento de comunicação entre as partes, buscando o entendimento e o consenso e facilitando a resolução do conflito.

\section{O PROCESSO DE DESJUDICIALIZAÇÃO}

Nos últimos anos houve um aumento quantitativo das demandas judiciais. Esse aumento gerou uma sobrecarga no sistema judiciário, resultando na morosidade e, consequentemente, na falta de efetividade deste sistema. Segundo matéria divulgada no Estadão sobre o relatório do Conselho Nacional de Justiça de 15/09/2015, apenas 28,6\% dos quase 100 milhões de processos que tramitaram em 2014 foram solucionados. Em comparação a 2013, houve um aumento de $0,8 \%$ no índice de processos que não foram resolvidos, e que atualmente está em $71,4 \% .^{2}$

Com vistas a melhorar o atendimento e desafogar o sistema judicial, o processo de desjudicialização vem crescendo no Brasil. Alguns institutos foram ampliados, possibilitando às partes resolver a demanda de forma extrajudicial, ou seja, através de um processo administrativo, utilizando para tanto os serviços das serventias extrajudiciais. Como exemplo, tem-se o divórcio, a separação, o inventário e partilha, e ainda, a regularização fundiária e a retificação de registro.

No ordenamento jurídico brasileiro, a primeira possibilidade de aplicação da demanda extrajudicial surgiu com a Lei $n^{\circ} 10.931 / 2004$, que ampliou a competência do oficial de Registro imobiliário nos casos de retificação, prevendo em seu artigo 213 que o Oficial será responsável pelo procedimento administrativo e suas etapas (Art. 213, Lei $\mathrm{n}^{\circ}$ 10.931/2004).

Em 2007, o legislador ampliou o rol trazendo a via administrativa como opção para as demandas de divórcio e separação (Art. 1.124-A CPC), partilha e inventário (Art. 982, CPC) possibilitando o tratamento por essa via, através da Lei ${ }^{\circ} 11.441 / 2007$, onde tais institutos, cumprindo os requisitos de consensualidade, prazos legais e algumas especificidades de cada caso, poder ser efetivados através da via extrajudicial por notários e registradores.

Atualmente, o instituto que entrou para o grupo de possibilidades extrajudiciais foi o da usucapião. A Lei 13.105/2015 trouxe inovação quando criou a opção de que seu

\footnotetext{
${ }^{2}$ Carvalho, Marco Antônio. Congestionamento do Judiciário aumenta e processos pendentes já são mais de 70 milhões. Disponível em: < http://politica.estadao.com.br/blogs/fausto-macedo/congestionamento-do-judiciarioaumenta-e-processos-pendentes-ja-sao-mais-de-70-milhoes/ >. Acesso em: 22 mar. 2016.
} 
reconhecimento seja feito através da via administrativa/extrajudicial, sendo processado diretamente no cartório do registro de imóveis da Comarca em que o imóvel está localizado (Art. 216-A, Lei 13.105/2015). Importante ressaltar que tal possibilidade não obsta que a parte o requeira pela via judicial.

Por fim insta apontar a mediação como consectário lógico do presente processo de desjudicialização. Não é difícil perceber a necessidade de colocação de tal instituto como um dos pilares do citado movimento. Quando o art. 42 da Lei n 13.140/2015 cita a mediação levada a efeito nas serventias extrajudiciais, está tão somente corroborando a tese apontada pelo presente, pois que a resolução mediática visaria não somente desafogar o judiciário, mas também, com já dito anteriormente, efetivar a satisfação dos indivíduos de forma mais célere e amigável, o que não se tem verificado nos meandros do Poder Judiciário.

\section{A PROXIMIDADE DOS CARTÓRIOS COM A POPULAÇÃO}

Um processo facilitador deve conservar suas características facilitadoras em todos os seus aspectos. O que se quer demonstrar com tais palavras é que, visualizando-se a mediação como um processo facilitador, além da celeridade, ausência de animosidade, redução dos custos da máquina judiciária, não se deve olvidar do acesso. Acesso no sentido de proximidade, isto é, não dificuldade de localização. Tais características são visualizadas nos órgãos do Judiciário, presentes apenas nos grandes centros urbanos, faltando tal acesso em cidades interioranas, distantes das metrópoles.

Exatamente nesse ponto, assume extrema importância a atividade notarial e registral, ou no linguajar mais tradicional e popular a atividade cartorária ou, simplesmente, os cartórios extrajudiciais.

Antes de passarmos à discussão e demonstração do quão as serventias extrajudiciais estão mais próximas da população que os órgãos jurisdicionais, faz-se necessário apresentar, mesmo que de forma breve, as características da atividade notarial e registral no país.

\section{1. A Atividade Notarial e Registral no Brasil}

A atividade notarial e registral no Brasil comporta serventias extrajudiciais com atribuições distintas definidas por lei. Várias são as normas que regem esta atividade. São elas: a própria constituição através do seu artigo 236, a Lei $n^{\circ} 6.015 / 73$, a Lei 8.935/94, a Lei 


\subsection{2/97, entre outras.}

Mas para o estudo em tela cumpre apresentar as diferentes modalidades de serventias extrajudiciais, seus responsáveis e suas especificidades. Didaticamente dividem-se em tabelionatos e registros públicos.

Os tabelionatos são divididos em tabelionados de notas cujo titular é o Tabelião de Notas e o tabelionato de Protesto cujo titular é o Tabelião de Protesto. Os registros públicos são divididos em registro de imóveis, registro civil das pessoas naturais, registro civil das pessoas jurídicas e registro de títulos e documentos, cujos titulares são os oficiais de registro de cada modalidade. Presentes em apenas alguns estados tem-se o Tabelionato de notas e registro de contratos marítimos, mais conhecidos como cartórios marítimos, cujos titulares são denominados tabeliães e oficiais de registro de contratos marítimos.

Todos os titulares dessas serventias recebem do Estado, através do poder judiciário, a delegação para a prática de função pública, porém exercida em caráter particular, o que significa que não são servidores públicos e nem remunerados pelo poder público, tendo toda responsabilidade administrativa dos funcionários por sua conta e risco. Suas remunerações são provenientes, tão somente, dos emolumentos recebidos, depois de repassados os percentuais devidos ao Estado. São profissionais do direito e recebem a delegação após concorrência pública promovida através de concurso público.

Entretanto, por serem delegatários do Estado respondem civil, administrativa e penalmente por seus atos e de seus prepostos. Civilmente, perante terceiros usuários dos serviços públicos; administrativamente, perante as corregedorias locais e regionais dos Tribunais de Justiça dos Estados, conforme um estatuto da categoria personificada na lei 8.935/94 e regulamentada pelos códigos de normas das corregedorias regionais dos estados; e, penalmente, pelos crimes funcionais, ou seja, pelos crimes praticados por funcionários públicos contra a administração, além das agravantes e qualificadoras dos demais crimes se na condição de funcionário público previstos no código penal, pois, por exercer a função é equiparado a funcionário público nos termos do artigo 327 do Código Penal.

Destarte, os delegatários são particulares que desempenham funções estatais, colaborando com a administração pública. São, portanto, agentes públicos da espécie particulares em colaboração com o Estado, não fazendo parte do quadro funcional do Estado e não sendo remunerados pelos cofres públicos, valendo-se somente dos emolumentos recebidos (art. 28, Lei $\mathrm{n}^{\mathrm{o}}$ 8.935/94), pelos usuários dos serviços prestados, para cobrir as despesas necessárias ao gerenciamento administrativo e financeiro das serventias (art. 21, Lei $\mathrm{n}^{\circ}$ 
8.935/94), repassando uma parte ao Estado que gira em torno de uns $40 \%$ em média, e o que sobra cobre sua própria remuneração (art. 1º, Lei n 10.169/2000).

Resumidamente, e, efetivamente não entrando nas peculiaridades específicas de cada cartório, temos a atividade notarial e registral regrada principalmente pela Lei Federal $\mathrm{n}^{\circ}$ 8.935/94, Lei dos Notários e Registradores (LNR), que regulamentou o artigo 236 da CFB e que dispõe em seus primeiros artigos que os serviços notariais e de registro são os de organização técnica e administrativa destinados a garantir a publicidade, autenticidade, segurança jurídica e eficácia dos atos jurídicos submetidos a eles.

Devem ser prestados de forma eficiente e adequada em locais de fácil acesso ao público, devendo todas as serventias funcionar diariamente no horário de expediente público, e ainda, no caso dos cartórios de registro civil das pessoas naturais, aos sábados, domingos e feriados podendo adotar regime de plantão (artigos $1^{\circ}$ e $4^{\circ}$ da LNR).

Em seu artigo $3^{\circ}$ dispõe, ainda que "Notário, ou tabelião, e oficial de registro, ou registrador, são profissionais do direito, dotados de fé pública, a quem é delegado o exercício da atividade notarial e de registro", e dentre elas, agora, a competência para a realização da mediação.

\section{2. A Efetiva Proximidade dos Cartórios frente à População}

Conforme pode-se inferir pela tabela abaixo, existem um total de 13.774 unidades de Cartórios no Brasil. A maior concentração encontra-se na região Sudeste do país com 5.318 unidades, equivalente a $41,9 \%$ do total de unidades no território, seguindo a distribuição populacional por região com $41,9 \%$ da população brasileira, com cerca de 85 milhões de habitantes nesta região.

Em segundo lugar, verifica-se a região Nordeste com 27,7\% dos Cartórios e 27,7\% da população do país, seguida da região Sul (14,3\% dos Cartórios e 14,3\% da população), da região Centro-Oeste (7,6\% dos Cartórios e 7,6\% da população) e da região Norte (8,5\% dos Cartórios e $8,5 \%$ da população) respectivamente.

No caso da região Norte, é possível verificar uma maior incidência populacional (17 milhões de habitantes) que a região Centro-Oeste (15 milhões de habitantes) com menor concentração de Cartórios em relação a mesma. 
A Mediação no Direito Brasileiro e sua Efetividade no Âmbito das Serventias Extrajudiciais

Tabela 1 - Distribuição de Cartórios X População segundo Região do País:

\begin{tabular}{|c|c|c|c|c|}
\hline Região do País & \multicolumn{2}{|c|}{ Cartórios } & \multicolumn{2}{c|}{ População (IBGE 2015) } \\
\hline & Quantidade & $\%$ & Quantidade & \% \\
\hline Centro-Oeste & 966 & $7,0 \%$ & 15.442 .232 & $7,6 \%$ \\
\hline Nordeste & 4.257 & $30,0 \%$ & 56.560 .081 & $27,7 \%$ \\
\hline Norte & 921 & $6,9 \%$ & 17.472 .636 & $8,5 \%$ \\
\hline Sudeste & 5.318 & $38,6 \%$ & 85.745 .520 & $41,9 \%$ \\
\hline Sul & 2.312 & $16,8 \%$ & 29.230 .180 & $14,3 \%$ \\
\hline Total & $\mathbf{1 3 . 7 7 4}$ & $\mathbf{1 0 0 , 0 \%}$ & $\mathbf{2 0 4 . 4 5 0 . 6 4 9}$ & $\mathbf{1 0 0 , 0 \%}$ \\
\hline
\end{tabular}

Fonte: Autoria própria (2016) ${ }^{3}$

Diante deste cenário, é importante destacar a importância da maior proximidade dos Cartórios com a população dos municípios brasileiros em relação às Comarcas dos Tribunais de Justiça para atuação nos casos de mediação de conflitos.

Sua proximidade não decorre apenas do número de unidades espalhadas pelo país, mas também de sua capilaridade, ou seja, estão presentes em localidades não alcançadas pelos órgãos do Poder Judiciário. Vejamos no quadro a seguir:

Tabela 2: Representação cartorária frente a população - Região Sudeste

\begin{tabular}{|c|c|c|c|c|c|c|c|c|}
\hline \multirow{2}{*}{$\begin{array}{c}\text { Unidade da } \\
\text { Federação }\end{array}$} & \multicolumn{2}{|c|}{$\begin{array}{c}\text { Serventias } \\
\text { Extrajudiciais } \\
\text { Cadastradas e Ativas }\end{array}$} & \multicolumn{2}{|c|}{ Comarcas } & \multicolumn{2}{|c|}{ Municípios } & \multicolumn{2}{c}{ População } \\
\cline { 2 - 10 } & Quant. & $\%$ & Quant. & $\%$ & Quant. & $\%$ & Quant. & $\%$ \\
\hline Espírito Santo & 357 & $6,7 \%$ & 108 & $13,5 \%$ & 78 & $4,7 \%$ & 3.929 .911 & $4,6 \%$ \\
\hline Minas Gerais & 3.009 & $56,6 \%$ & 296 & $37,0 \%$ & 853 & $51,1 \%$ & 20.869 .101 & $24,3 \%$ \\
\hline Rio de Janeiro & 406 & $7,6 \%$ & 81 & $10,1 \%$ & 92 & $5,5 \%$ & 16.550 .024 & $19,3 \%$ \\
\hline São Paulo & 1.546 & $29,1 \%$ & 316 & $39,5 \%$ & 645 & $38,7 \%$ & 44.396 .484 & $51,8 \%$ \\
\hline
\end{tabular}

Fazendo um comparativo entre os dados levantados, é possível observar que as serventias extrajudiciais têm uma possibilidade de contato muito maior com a população.

No levantamento feito na região Sudeste, verifica-se que há uma serventia extrajudicial para cada 16.688 habitantes, enquanto que em relação às comarcas esse número sobe para 107.048 habitantes, ou seja, os cartórios têm quase dez vezes mais contato com a população, isso na região apontada.

Se a relação se voltar à quantidade de municípios, novamente verificamos uma superioridade em relação aos cartórios, pois enquanto há 3 cartórios, em média, por município,

\footnotetext{
${ }^{3}$ Dados levantados junto ao CNJ e IBGE.

${ }^{4}$ Dados levantados juto ao CNJ; IBGE e aos Tribunais de Justiça do ES; MG; RJ e SP.
} 
a quantidade de comarcas não alcança o número de municípios apresentado acima, ou seja, para atender um total de 1.668 municípios na região sudeste temos disponíveis apenas 801 Comarcas/fóruns contra um total de 5.318 cartórios disponíveis.

Fica evidente, portanto, que diante da possibilidade da população recorrer aos cartórios para a realização da mediação, haverá maior amplitude do acesso à justiça, atualmente inviabilizada pela pequena quantidade de comarcas, em regra, localizadas apenas em regiões metropolitanas deixando os municípios menores de fora.

\section{A CONTROVÉRSIA QUANTO À IMPLANTAÇÃO DA MEDIAÇÃO NOS CARTÓRIOS DE SÃo PAULO E QUE FORAM OBJETOS DE PCA NO CNJ ANTES DA LEI No 13.140/15}

O Tribunal de Justiça do Estado de São Paulo através da Corregedoria Geral da Justiça, em uma iniciativa inédita no país, autorizou, através do provimento $\mathrm{n}^{\circ} 17$, de 5 de junho de 2013 , os 1.535 cartórios extrajudiciais a solucionar conflitos por meio de atos de mediação e conciliação. Segundo o Tribunal esta prática de mediação e conciliação já ocorre nas serventias extrajudiciais, só que de maneira informal, pois na maioria das vezes é o único braço da justiça em pequenas cidades.

O provimento alinhou-se aos propósitos instituídos pela resolução $\mathrm{n}^{\circ} 125$ do Conselho Nacional de Justiça e dispôs como um dos objetivos a consolidação de uma política pública permanente de incentivo e aperfeiçoamento dos mecanismos consensuais de solução de litígios. Todavia, deixa claro que a conciliação e a mediação realizada nas serventias extrajudiciais restringem-se apenas a direitos patrimoniais disponíveis, isto é, bens e direitos que o titular pode livremente renunciar, dispor ou transacionar.

Ocorre que liminar concedida pela conselheira Gisela Gondin Ramos no dia 26/08/2013 e confirmada pelo Plenário do Conselho Nacional de Justiça no dia 10/09/2013, suspendeu a entrada em vigor do provimento e, consequentemente, a autorização aos cartórios de São Paulo para que promovessem a mediação e conciliação extrajudiciais. Tal decisão ocorreu em atendimento a pedido impetrado pelos Conselho Federal da Ordem dos Advogados do Brasil, da seccional paulista da OAB; Associação dos Advogados de São Paulo (Aasp) e Instituto dos Advogados de São Paulo (IASP).

Dentre os argumentos apresentados pela OAB de São Paulo está o de que "não seria razoável que os cartórios, que possuem função registral, busquem substituir a sociedade e as instituições para realizar a mediação", considerando o Provimento n 17/2013 CGJ/SP ilegal. 
Alegam ainda que há um desrespeito ao princípio da competência, na medida em que tal provimento foi editado por quem não teria competência formal para tal.

Ao conceder a liminar, o CNJ afirmou que o ato administrativo impugnado invade a esfera de regulamentação reservada à Lei, ferindo o artigo 37 da Constituição Federal, extrapolando assim as funções dos notários e registradores. Alega ainda que não é possível embasar tal provimento na resolução 125 do próprio $\mathrm{CNJ}$, na medida em que esta aponta direto e efetivo controle dos Centros Judiciários de Solução de Conflitos e Cidadania. Sendo assim, tal decisão do TJ paulista criaria um mecanismo paralelo de resolução de conflitos, cuja regulamentação escaparia ao controle da política judiciária nacional.

Contudo, com a entrada em vigor do novo Código de Processo Civil, mudança significativa veio de encontro à fundamentação dada pelo CNJ, para a concessão da liminar que suspendeu a aplicação do provimento do TJSP em comento, uma vez que no corpo da lei 13.105/2015, menciona expressamente que os Tribunais criarão centros judiciários de solução de conflitos que realizarão audiências de conciliação e mediação, contudo a composição e a organização dos referidos centros, devem obedecer às normas dos respectivos tribunais e orientação normativa do CNJ (Artigo 165 e $\S 1^{\circ}$ da Lei 13.105/2015), além de prever no artigo 175, outras formas de conciliação e mediação extrajudiciais, que poderão ser realizadas por profissionais independentes ou adstrito a órgãos institucionais desde que regulamentado por lei específica.

Mas especificamente ainda, a Lei de Mediação (Lei no 13.140/15) trouxe em seu artigo 42 a legitimidade procedimental da mediação no âmbito dos cartórios, reconhecendo legalmente a atribuição dos notários e registradores, bem como de seus prepostos para o exercício da mediação extrajudicial, ou mesmo judicial, diante da possibilidade do credenciamento de câmaras privadas de mediação realizada tribunal competente.

Desta forma, a lei $\mathrm{n}^{\mathrm{o}} 13.140 / 15$ afastou qualquer possibilidade de impedimento da realização da mediação no âmbito das serventias extrajudiciais.

\section{A PRÉ-EXISTÊNCIA DO PROCEDIMENTO DE MEDIAÇÃO NAS SERVENTIAS EXTRAJUDICIAIS ANTES DA LEI No 13.140/15}

A iniciativa do TJSP através do Provimento n. ${ }^{\circ}$ 17/2013, gerou um movimento de normatização nos âmbitos dos Tribunais de Justiça de alguns Estados, v.g, Alagoas, Ceará, Maranhão e Mato Grosso, que apesar de não haver uma autorização legal expressa que legitimasse a realização da mediação no âmbito dos cartórios, normatizaram-na através de provimentos tendo como fonte a Resolução n. ${ }^{\circ} 125$ do CNJ. 
Efetivaram, portanto, o procedimento de mediação através de provimentos das CGJ, v.g, no Ceará, através do provimento n 12 da CGJ/CE de 21 de junho de 2013; Alagoas, através do provimento ${ }^{\circ} 18$ da CGJ/AL, de 05 de agosto de 2013; Mato Grosso, através do provimento $\mathrm{n}^{\circ} 29$ da CGJ/MT, de 08 de agosto de 2013; e, Maranhão, através do provimento $\mathrm{n}^{\circ} 04$ da CGJ/MA, de 09 de abril de 2014.

No Estado do Maranhão, o Cartório do $2^{\circ}$ Ofício Extrajudicial da Comarca de Chapadinha, foi o primeiro a realizar audiência de conciliação, desde a assinatura do provimento 04/2014. A audiência foi conduzida pela tabeliã titular do cartório, que participou da primeira turma do curso de formação de conciliadores realizado pelo Núcleo Permanente de Métodos Consensuais de Solução de Conflitos do Tribunal de Justiça do Maranhão, em parceria com o Instituto de Estudos de Protesto de Títulos do Brasil (IEPTB/MA).

Fica evidente que apesar das iniciativas terem sua inspiração no provimento do TJ de São Paulo, cada estado promoveu regulamentação com peculiaridades distintas que de uma forma ou de outra diferenciam a forma de acesso à mediação pelos interessados, havendo necessidade de um provimento em âmbito nacional por parte do Conselho Nacional de Justiça (CNJ) visando uniformizar a implementação da técnica de mediação nas serventias extrajudiciais, sobretudo agora em que há autorização legislativa introduzida expressamente pela lei $n^{\circ} 13.140 / 15$.

\section{A NECESSÁRIA INTERPRETAÇÃO DO ARTIGO 42 DA LEI DE MEDIAÇÃO}

A lei de mediação surge diante da falência do Estado-juiz como única instância capaz de dirimir os conflitos existentes na sociedade, deslocando para o particular a possibilidade de autocomposição mediante o uso da mediação extrajudicial.

A mediação, desta forma, nesse momento é introduzida legalmente no ordenamento jurídico brasileiro através das leis 13.105/15 e a 13.140/15 como uma primeira ferramenta na resolução de conflitos, ou seja, como o meio mais adequado de pacificação social, no momento em que a litigiosidade no país se mostra com volume exacerbado de processos judiciais.

Assim, com o intuito de tornar a mediação mais acessível à população, o legislador previu que poderia funcionar como medidor extrajudicial qualquer pessoa capaz que tivesse a confiança das partes e que fosse capacitada para realizar a composição do conflito, sendo certo que tal pessoa não necessitaria fazer parte ou estar inscrito em qualquer tipo de conselho ou entidade de classe (art. $9^{\circ}$ da Lei $\left.{ }^{\circ} 13.140 / 15\right)$. 
$\mathrm{O}$ art. 42 dispõe que as serventias extrajudiciais podem realizar a mediação, desde que no âmbito de suas competências. Ou seja, numa interpretação literal, as serventias extrajudiciais estariam limitadas a exercer a atividade de mediação quando o objeto do conflito se adequar às atribuições específicas das serventias. Como visto anteriormente, as serventias possuem atribuições específicas para a prática de seus atos, seja como notários/tabeliães ou registradores.

Diante dessa situação hipotética, imagina-se o absurdo, por exemplo, de um desentendimento de vizinhos onde um abalroou o veículo do outro ao sair da garagem e resolvem procurar o cartório mais próximo que sabem competente para a realização da mediação para firmarem um acordo de como será ressarcido o prejuízo, trazendo segurança jurídica aos interessados e pacificação da animosidade.

Todavia, recebem a resposta do Oficial de Registro Civil das Pessoas Naturais que, apesar de ser mediador extrajudicial, a questão deles não pode ser mediada por ele por incompetente quanto ao objeto do conflito. Mas que poderiam se deslocar até o centro da cidade na busca de outro cartório competente, ou então, buscar na comunidade local qualquer mediador extrajudicial para realiza-la.

Ora, cumpre clarear, que seria contrassenso do legislador prever no artigo $9^{\circ}$ da lei que qualquer pessoa capaz, que tenha a confiança das partes, pode realizar a mediação e, ao mesmo tempo, restringir no artigo 42 a atuação dos titulares e prepostos das serventias extrajudiciais, reduzindo seu campo de atuação.

Por óbvio, os titulares e prepostos de cartório devem possuir os requisitos exigidos pelo artigo $9^{\circ}$, posto que senão, não estarão habilitados a serem mediadores. Porque a lei limitaria sua atuação? Que outro mediador apto a aplicar a técnica da mediação e legitimamente escolhido pelos interessados estará impedido de atuar na resolução de conflitos?

Tal restrição acabaria por limitar a acessibilidade dos interessados, principalmente das populações mais carentes, ao procedimento da mediação de uma forma mais ampla, isso porque, estreme de dúvidas, as serventias extrajudiciais por estarem instaladas em todas as cidades brasileiras, bem como em todos os distritos no que tange aos registros civis das pessoas naturais, possuem um alcance maior do que o poder Judiciário em sua função jurisdicional, ou mesmo na mediação judicial, visto que as comarcas existentes no território nacional são em número menor do que as serventias extrajudiciais, como demonstrado anteriormente.

Neste ponto, a que se ter em conta a necessária interpretação teleológica diante da racio da norma na redação do referido artigo, uma vez que distanciaria da mesma a finalidade precípua da mediação, qual seja, a redução da excessiva judicialização dos conflitos, o 
empoderamento das partes na resolução de seus próprios conflitos; que só se efetivará com a máxima ampliação do acesso a Justiça através dessas estruturas de mediação, sejam judiciais ou extrajudiciais.

Quanto à pessoa do oficial delegatário, imperioso demonstrar que o mesmo possui qualidades tanto humanas quanto profissionais que o qualificam para o exercício pleno da mediação. Este após rigoroso procedimento legal recebe a delegação do serviço público e fé pública para os atos que venha a praticar.

Diante disso, estaria sendo não só desprestigiado, como também subestimado pelo legislador quando tem sua atuação limitada para atuar somente no âmbito da competência de suas serventias, sendo que para realização da mediação é de sua essencialidade, pessoa capacitada a aplicar as técnicas da mediação e a confiança dos mediandos quanto a pessoa do mediador.

Além das considerações analisadas acima, outras questões foram observadas nas pesquisas realizadas. As Corregedorias de Justiça nos Estados que já possuem provimento de autorização e implementação do processo de mediação nas serventias extrajudiciais, como é o caso do Ceará, do Maranhão, do Mato Grosso, de São Paulo e de Alagoas adotaram de forma unânime outros princípios em complementação àqueles constantes da lei, como exemplo, o princípio do empoderamento das partes e o da validação, uma vez que estes visam estimular os interessados a aprender como melhor resolver os seus conflitos futuros a partir da vivência experimentada na autocomposição, bem como passarem a se perceber como seres humanos merecedores de atenção e respeito.

Outro ponto relevante observado nos provimentos editados nesses estados é o da autorização para que seja dirigido a qualquer notário ou registrador, independentemente da especialidade da serventia que seja titular, os casos postos a mediação. Ou seja, o oficial do cartório não fica adstrito a mediar somente às questões que estejam ligadas a competência funcional de sua serventia, podendo tanto o notário como o registrador, seja qual for o problema suscitado pelas partes, atuar como mediador. Tal permissão visa ampliar a área de abrangência e assim alcançar o maior número de pessoas possíveis, não necessitando que a parte interessada tenha de se deslocar para locais distantes de suas residências.

\section{CONCLUSÃo}

De todo o exposto se observa, com clareza solar, que as serventias extrajudiciais 
devem ocupar uma posição de extrema importância frente às formas de solução pacífica de conflitos, principalmente no que se refere a mediação.

Isso não apenas no aspecto legal, como se deflui das recentes normas, delegando tal responsabilidade às atividades notariais e registrais, mas também socialmente, ao se verificar a verdadeira conjunção de fatores que corroboram o ora exposto, seja pelo fato das serventias judiciais estarem muito mais próximas dos indivíduos, ou pela simples análise quantitativa, demonstrando a superioridade numérica dos cartórios frente aos órgãos jurisdicionais.

A Lei 13.140/2015 não tem como objeto restringir as possibilidades de mediação no âmbito da atividade cartorária. Pois, o legislador deixaria de dar um grande passo em apoio à função jurisdicional do Estado, fraco em seu caminhar, lento em seu labor e carente de meios que verdadeiramente efetivem a justiça em nosso país.

Assim, diante de todo o expendido acima, conclui-se que o legislador, apesar de fazêlo apenas no artigo 42, reconheceu a necessidade de utilização das serventias extrajudiciais na implementação da cultura de paz e da autocomposição na resolução dos conflitos.

O que se tentou demonstrar com as pesquisas realizadas é que o legislador lançou mão da capilaridade e da capacidade técnica das serventias extrajudiciais como vem fazendo nas últimas décadas, diante do fenômeno da desjudicialização, e ainda, do fato de que as serventias extrajudiciais não demandam recursos públicos para sua manutenção como ocorre nas estruturas judiciais, que oneram pesadamente os cofres públicos.

Portanto, as serventias extrajudiciais ou os cartórios como a população costuma chamar, têm a potencialidade de alcançar todos os distritos de todas as cidades brasileiras como verdadeiros polos de mediação, atingindo toda população deste imenso país, sendo um verdadeiro longa manus do Estado, desafogando o Estado Juiz nas ações relativas aos direitos disponíveis, e, mesmo os indisponíveis transacionáveis, sem custo nenhum para os cofres públicos, contribuindo de maneira efetiva para o processo de desjudicialização, de forma eficaz e menos onerosa para todo o povo brasileiro. 


\section{BIBLIOGRAFIA}

ARGENTINA. Ley n 24.573 de 1996. Sustitúyese con carácter obligatorio la mediación previa a todo juicio. Disposiciones Generales. Procedimiento. Registro de Mediadores. Causales de Excusación y Recusación. Comisión de Selección y Contralor. Retribución del Mediador. Fondo de Financiamiento. Honorarios de los Letrados de las Partes. Cláusulas Transitorias. Modificaciones al Código Procesal Civil y Comercial de la Nación. Disponível em: <http://www.infoleg.gov.ar/infolegInternet/anexos/25000- 29999/29037/norma.htm>. Acesso em: 22 mar. 2016.

. Ley n ${ }^{\circ} 26.589$ de 2010. Establécese con carácter obligatorio la mediación previa a procesos judiciales. Disponível em: <http://infoleg.mecon.gov.ar/infoleg Internet/anexos/165000169999/166999/norma.htm>. Acesso em: 22 mar. 2016.

BAPTISTA, Bárbara Gomes Lupetti; FILPO, Klever Paulo Leal. Conciliando o inconciliável: entre o produtivismo judicial e a busca do consenso. In: Justiça mediática e preventiva [Recurso eletrônico on-line] organização CONPEDI/UFS; Coordenadores: Adriana Silva maillart, Jamile Bergamaschine Mata Diz, Mauto José Gaglietti. Florianópolis : CONPEDI, 2015.

BELEZA, Flávia Tavares. Estudar em paz: Mediação de conflitos no contexto escolar. Disponível em:

<http://periodicos.unb.br/index.php/participacao/article/viewFile/6323/5902 2. Acesso em: 11 abr. 2016.

BRASIL. Conselho Nacional de Justiça. Azevedo, André Gomma de (Org.). Manual de Mediação Judicial. 5. ed. Brasília/DF, 2015.

. Conselho Nacional de Justiça. Resolução $n^{\circ}$ 125/2010. Disponível em: <http://www.cnj.jus.br/busca-atos-adm?documento=2579>. Acesso em: 22 mar. 2016.

Conselho Nacional de Justiça. Serventias Extrajudiciais cadastradas e ativas. Disponível em: <http://www.cnj.jus.br/corregedoria/justica_aberta/?>. Acesso em: 22 mar. 2016. 
Conselho Nacional do Ministério Público. Diálogos e Mediação de Conflitos

nas Escolas:Guia Prático para Educadores. Brasília, CNMP, 2014. Disponível em http://www.cnmp.mp.br/portal_2015/images/stories/Comissoes/CSCCEAP/Di\%C3\%A1 logos_e_Media\%C3\%A7\%C3\%A3o_de_Conflitos_nas_Escolas_-_Guia_Pr\%C3\% A1tico _para_Educadores.pdf. Acesso em: 11 abr. 2016.

Corregedoria Geral do Estado do Rio de Janeiro. Mapa das Comarcas o Rio de janeiro. Disponível em: 〈http://cgj.tjrj.jus.br/documents/10136/1628206/mapa-rj-2015.pdf〉. Acesso em: 22 fev. 2016.

Instituto Brasileiro de Geografia e Estatística - IBGE. Disponível em: < http://www.cidades.ibge.gov.br/xtras/home.php>. Acesso em: 16 mar. 2016.

. Lei $n^{0}$ 13.105, de 16 de março de 2015. Código de Processo Civil. Disponível em: < http://www.planalto.gov.br/ccivil_03/_ato2015-2018/2015/lei/113105.htm>. Acesso em: 20 mar. 2016.

. Lei $n^{0}$ 13.140, de 16 de junho de 2015. Dispõe sobre a - mediação entre particulares como meio de solução de controvérsias e sobre a autocomposição de conflitos no âmbito da administração pública; altera a Lei n⿳⺈-9.469, de 10 de julho de 1997, e o Decreto no 70.235, de 6 de março de 1972; e revoga 0 § $2^{\circ}$ do art. $6^{0}$ da Lei $\quad n \underline{n}-9.469, \quad$ de $\quad 10$ de julho de 1997. Disponível em:

<http://www.planalto.gov.br/ccivil_03/_Ato2015-2018/2015 /Lei/L13140.htm>. Acesso em: 15 mar. 2016.

Ministério da Justiça. Guia de orientações para proposição de projeto - e preenchimento do SICONV. Brasil: Ministério da Justiça, 2013.

. Tribunal de Justiça do Estado de Minas Gerais. Lista das comarcas. Disponível em: < http://www8.tjmg.jus.br/juridico/comarcas.html>. Acesso em: 22 fev. 2016.

. Tribunal de Justiça do Estado de São Paulo. Regiões administrativas judiciárias.

Disponível em: $\quad$ e $\quad$ http://www.tjsp.jus.br/Download/Imagens/MapaImpressao CircunscricaoNumero.pdf>. Acesso em: 22 fev. 2016. 
. Tribunal de Justiça do Estado do Espírito Santo. Mapa das Comarcas do Espírito

Santo. Disponível em: <http://www.integrawebsites.com.br/versao_1/arquivos /1e9377df9d4b491a8429a109287833df.pdf>. Acesso em: 22 fev. 2016.

CARVAlHO, Marco Antônio. Congestionamento do Judiciário aumenta e processos pendentes já são mais de $\mathbf{7 0}$ milhões. Jornal Estadão. Disponível em:

$<$ http://politica.estadao.com.br/blogs/fausto-macedo/congestionamento-do-judiciarioaumenta- e-processos-pendentes-ja-sao-mais-de-70-milhoes/ >. Acesso em: 22 mar. 2016.

Colégio Notarial do Brasil. Conselho Federal. Cartório de Chapadinha é o primeiro a realizar conciliação e mediação no Maranhão. Publicado em 20 jan. 2016. Disponível em:

<http://www.notariado.org.br/index.php?pG=X19leGliZ

V9ub3RpY2lhcw==\&in=Njg3Mg==>. Acesso em: 16 mar. 2016.

CHRISPINO, Álvaro. Gestão do conflito escolar: da classificação dos conflitos aos modelos de mediação. Ensaio: Avaliação de Políticas Públicas em Educação, Rio de Janeiro, v.15, n.54, p. 1128, jan./mar. 2007.

DELGADO, José. Constitucionalidade da mediação. In: Mediação : um projeto inovador / José Delgado et al. Brasília : Centro de Estudos Judiciários, CJF, 2003. Disponível em:

<file://C:/Users/INV/Downloads/Volume\%2022\%20-\%20MEDIACAO\%20UM\%20 PROJETO \%20INOVADOR.pdf >. Acesso em: 22 mar. 2016.

FILPO, K. P. L. ; BAPTISTA, B. G. L. ; BORZINO, T. Os Caminhos da Mediação do Brasil e na Argentina. In: Sociologia do Direito em Movimento - Perspectivas da América Latina, 2015, Canoas. Anais do Congresso Sociologia do Direito em Movimento, 2015.

, K. P. L. Conflitos escolares, espiral do conflito e por que não a mediação. In: Adriana Goulart de Sena Orsini; Adriana Silva Maillart; Nivaldo dos Santos. (Org.), XXIV Congresso Nacional do Conpedi - Formas Consensuais de Solução de Conflitos, Atas... Belo Horizonte: UFMG/FUMEC/Dom Helder Câmara, 2015. Florianópolis: Conpedi, 2015, v. 1, p. 357-374.

Klever Paulo Leal. Conflitos escolares, espiral do conflito e (por que não?) a mediação. In: Formas consensuais de solução de conflitos [Recurso eletrônico on-line] organização CONPEDI/UFMG/FUMEC/Dom Heder Câmara; Coordenadores: Adriana Goulart de Sena Orsini, Adriana Silva Maillart, Nivaldo dos Santos. Florianópolis : CONPEDI, 2015. 
FRANÇA. Une nouvelle ambition pour les villes. Rapport à monsieur Claude Bartolone, ministre delegue à la Ville et Monsieur Paul Picard. 2000. Disponível em: <i.ville.gouv.fr/divbib/doc/rapbrevanpicard.pdf>. Acesso em: 16 mar.2016.

LUCIANO, Antoniele. Cartórios vão ajudar na solução de conflitos. Disponível em: $<$ http://www.anoregpr.org.br/index.php?option=com_content\&view=article\&id=4811: cartor i os-vao-ajudar-na-solucao-de-conflitos>. Acesso em: 16 mar. 2016.

SANTOS, Alex Kniphoff dos. Mediação: da teoria à prática. In: Mediação enquanto política pública [Recurso eletrônico] : o conflito, a crise da jurisdição e as práticas mediativas

/ organizadores: Fabiana Marion Splenger, Theobaldo Spengier Neto. 1. ed. Santa Cruz do Sul : EDUNISC, 2012.

SILVA, Marcelo Lessa da. Regime Recursal Registral no Brasil: O procedimento de dúvida. Um modelo eficaz? Uma análise com o direito comparado. In: CONPEDI/UFS;Flávia Moreira Guimarães Pessoa; Natercia Sampaio Siqueira; Paulo Roberto Coimbra Silva. (Org.). Processo, jurisdição e efetividade da justiça. 1ed.Florianópolis: CONPEDI, 2015, v. 1, p. 601-620.

VASCONCELOS, Carlos Eduardo de. Mediação de conflito e práticas restaurativas. - São Paulo: Método, 2008.

VEZULLA, Juan Carlos. A mediação para uma análise da abordagem dos conflitos dos direitos humanos, o acesso à justiça e o respeito à dignidade humana. In Mediação de conflitos/ Luciana Aboim Machado Gonçalves da Silva, organizadora. São Paulo: Atlas, 2013.

WALTRICH. Dhieimy Quelem, A medição comunitária como instrumento democratizador da justiça. In: Mediação enquanto política pública [ recurso eletrônico]: o conflito, a crise da jurisdição e as práticas mediativas / organizadores: Fabiana Marion Spengler, Theobaldo Spengler Neto, 1. ed. Santa Cruz do Sul : EDUNISC, 2012. 